RESEARCH ARTICLE

\title{
Monolithic edge-cladding process for the elliptical disk of N31-type Nd-doped high-power laser glass
}

\author{
Huiyu Chen ${ }^{1,2}$, Min Qian ${ }^{1,2}$, Youkuo Chen ${ }^{1}$, Xin Wang ${ }^{1}$, Jingping Tang ${ }^{1}$, Lei Wen ${ }^{1}$, Junjiang $\mathrm{Hu}^{1}$, \\ Wei Chen ${ }^{1}{ }^{1}$, Shubin $\mathrm{Chen}^{1}$, and Lili Hu${ }^{1}$ \\ ${ }^{1}$ Key Laboratory of Materials for High Power Laser, Shanghai Institute of Optics and Fine Mechanics, Chinese Academy of Sciences, \\ Shanghai 201800, China \\ ${ }^{2}$ Center of Materials Science and Optoelectronics Engineering, University of Chinese Academy of Sciences, Beijing 100049, China \\ (Received 16 March 2021; revised 18 January 2022; accepted 28 February 2022)
}

\begin{abstract}
This paper investigates the monolithic edge-cladding process for the elliptical disk of N31-type Nd-doped phosphate laser glass, which will be utilized under liquid cooling conditions for high-power laser systems. The thermal stress, interface bubbles and residual reflectivity, which are due to high-temperature casting and bonding during the monolithic edge-cladding process, are simulated and determined. The applied mould is optimized to a rectangular cavity mould, and the casting temperature is optimized to $1000^{\circ} \mathrm{C}$. The resulting lower bubble density makes the mean residual reflectivity as low as $6.75 \times 10^{-5}$, which is enough to suppress the amplified spontaneous emission generated in the Nd-glass disk, and the resulting maximum optical retardation is converged to $10.2-13.3 \mathrm{~nm} / \mathrm{cm}$, which is a favourable base for fine annealing to achieve the stress specification of less than or equal to $5 \mathrm{~nm} / \mathrm{cm}$. After fine annealing at the optimized $520^{\circ} \mathrm{C}$, the maximum optical retardation is as low as $4.8 \mathrm{~nm} / \mathrm{cm}$, and the minimum transmitted wavefront peak-to-valley value is 0.222 wavelength $(632.8 \mathrm{~nm})$. An N31 elliptical disk with the size of $194 \mathrm{~mm} \times 102 \mathrm{~mm} \times 40 \mathrm{~mm}$ can be successfully cladded by the optimized monolithic edge-cladding process, whose edge-cladded disk with the size of $200 \mathrm{~mm} \times 108 \mathrm{~mm} \times 40 \mathrm{~mm}$ can achieve laser gain one-third higher than that of an N21-type disk of the same size.
\end{abstract}

Keywords: interface bubble; monolithic edge-cladding process; N31-type Nd-doped phosphate laser glass; residual reflectivity; stress birefringence

\section{Introduction}

Edge-cladding has long been an effective method to suppress transverse amplified spontaneous emission and parasitic oscillation, which severely affect the magnitude and the spatial distribution of the inversion occurring in media with a large laser gain ${ }^{[1]}$. Only if these media with a certain shape and size are edge-cladded as designed can much more laser pulse energy be extracted from the media. The developed high-energy and high-power laser systems will be exploited to support ignition science ${ }^{[2]}$ and unprecedented extreme physics ${ }^{[3]}$. No matter whether the laser systems utilize laser glass or laser crystal, and no matter whether they run at a lower or higher repetition rate, effi-

Correspondence to: W. Chen, Key Laboratory of Materials for High Power Laser, Shanghai Institute of Optics and Fine Mechanics, Chinese Academy of Sciences, Shanghai 201800, China. Email: weichen@siom.ac.cn cient edge-cladding is always required ${ }^{[2,3]}$. Regarding diverse laser systems with different laser media of different shape and size, the utilized laser media need respectively corresponding solutions of the edge-cladding process. The solutions include solder glass cladding ${ }^{[4]}$, liquid edge-cladding ${ }^{[5]}$, monolithic edge-cladding ${ }^{[6]}$, sealing edge-cladding ${ }^{[7,8]}$, fusing edge-cladding ${ }^{[9]}$, the leak method by processing the gain medium edge into an arris ${ }^{[10,11]}$, the inorganic edge-cladding structure based on hydroxide-catalysis bonding ${ }^{[12,13]}$ and composite polymer-glass edge-cladding ${ }^{[14-16]}$.

The composite polymer-glass edge-cladding is a process in which the flat strip of $\mathrm{Cu}$-doped edge-cladding glass will be bonded to the peripheral side-edge of the laser glass slab by an epoxy structural adhesive ${ }^{[14-16]}$. It has been applied for LHG-8/LG-770 ${ }^{[17]}$ and N31 ${ }^{[18]} \mathrm{Nd}$-glass rectangular slabs respectively installed at the National Ignition Facility ${ }^{[19]}$, the Laser Megajoule facility ${ }^{[20]}$ and the SG-III laser facility $^{[21]}$. Although this is a very good and commonly used

(C) The Author(s), 2022. Published by Cambridge University Press in association with Chinese Laser Press. This is an Open Access article, distributed under the terms of the Creative Commons Attribution-NonCommercial-NoDerivatives licence (https://creativecommons.org/licenses/by-nc-nd/4.0/), which permits non-commercial re-use, distribution, and reproduction in any medium, provided the original work is unaltered and is properly cited. The written permission of Cambridge University Press must be obtained for commercial re-use or in order to create a derivative work. 
edge-cladding process, it is not suitable for special-shaped laser glass components, such as elliptical and circular disks. In particular, such a process cannot be applied at the present time when the amplifier glass slabs need to be immersed in organic and/or inorganic coolants for a high repetition rate ${ }^{[22-25]}$. The coolants would easily dissolve the bonding agent, such as the used epoxy structural adhesive, that combines the edge-cladding glass strip with the laser glass slab.

To eliminate the epoxy structural adhesive, the monolithic edge-cladding or the sealing edge-cladding process could be applied. In these two processes, there is no epoxy structural adhesive between the $\mathrm{Cu}$-containing edge-cladding glass and the Nd-doped laser glass. The interface is an immediate consequence, as the edge-cladding glass is directly bonded to the side-edge of $\mathrm{Nd}$-glass at a certain high temperature, which can be used for a long time under the strong liquid cooling condition.

However, for the sealing edge-cladding process, the slurry formed by mixing low melting temperature cladding glass powders with organic dispersant will be coated on the sideedge and then heated at a temperature such that Nd-glass is not softened or deformed. It could be applied successfully for N21 Nd-doped phosphate laser glass ${ }^{[26]}$, since its transition temperature is as high as $550^{\circ} \mathrm{C}$. As for $\mathrm{N} 31 \mathrm{Nd}$-doped phosphate laser glass, its laser parameters are much better, but its transition temperature is only around $450^{\circ} \mathrm{C}^{[18]}$. If choosing the sealing edge-cladding process for N31, the temperature used to heat the sealed edge-cladding glass should be lowered ${ }^{[7]}$. However, a lower temperature sealing process will produce more bubbles ${ }^{[8]}$, pits and carbide contaminants at the cladding interface. These defects increase the residual reflectivity (about $0.1 \times 10^{-2}-25 \times 10^{-2}$ ), which cannot fully suppress the effects due to amplified spontaneous emission and parasitic oscillation.

The monolithic edge-cladding process is now applied and developed for N31 Nd-doped phosphate laser glass. The bonding strength between the laser glass and the edgecladding glass, which is produced by the melt bonding process of the monolithic edge-cladding process, is much higher than that for the composite polymer-glass edge-cladding and sealing edge-cladding processes. Under high-energy/power laser working conditions, the monolithic edge-cladding N31 elliptical glass disk can be immersed in liquid coolants without erosion of the cladding interface. These cladded disks would achieve a higher laser repetition rate and would be more reliable during long-term laser operation.

In the following, the essential process steps of the developed monolithic edge-cladding, numerical simulation and test methods for the cladded disk are introduced firstly in Section 2. Then in Section 3.1, according to the numerical simulation for the thermal stress due to the high-temperature casting, a rectangular cavity mould will be applied in the process instead of the previously used elliptical cavity mould.

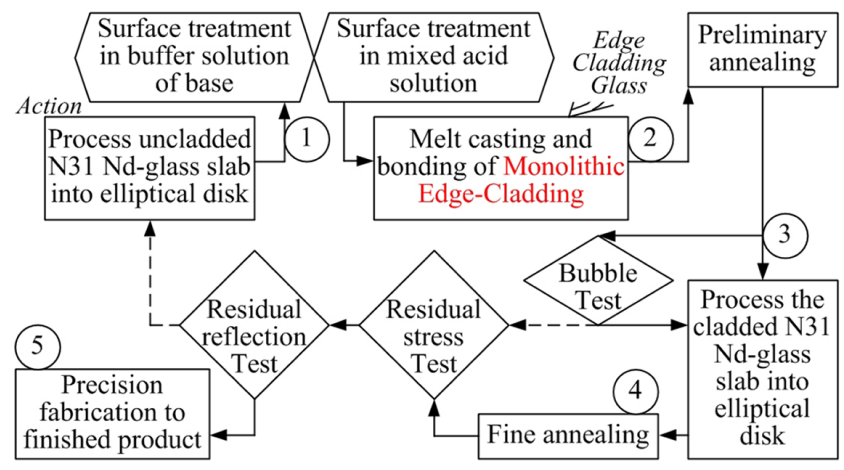

Figure 1. Essential flow chart of the monolithic edge-cladding process for the elliptical disk of N31-type Nd-doped phosphate laser glass.

The determined stress distribution not only shows a small thermal stress by such a rectangular mould process, but also indicates an optimized casting temperature for the monolithic edge-cladding. Subsequently, in Sections 3.2 and 3.3 , the number and size of the cladding interface bubbles and their affected residual reflectivities are determined to analyse the effects due to the casting temperature. Finally, in Section 3.4, the fine annealing temperature is optimized, and the stress birefringence and the transmitted wavefront specifications can be achieved for the real cladded products by the optimized monolithic edge-cladding process, successfully meeting high-power laser applications.

\section{Experiments and simulation}

\subsection{Monolithic edge-cladding process}

The essential flow chart of the monolithic edge-cladding process is shown in Figure 1, which mainly consists of five steps: (1) surface treatments for the side-edge of the laser glass disk to be cladded; (2) melt casting and bonding processes of the monolithic edge-cladding; (3) preliminary annealing and optical fabrication; (4) fine annealing; and (5) optical precision fabrication to the finished product.

The N31 Nd-doped phosphate laser glass slab will be shaped to an elliptical disk with the peripheral side-edge polished. The surface of the polished side-edge will be treated in a buffer solution of base firstly, and then in a mixed acid solution. It is important to carry out such surface treatments, step 1 in Figure 1, aiming to remove those surface defects and particulate impurities on the surface and subsurface that are generated during the optical cold processing.

After being washed with deionized water and high-purity alcohol, the elliptical laser glass disk will be placed in an elliptical or rectangular cavity mould made of steel, and then heated within a muffle furnace (Zufa Industry, China). The temperature will be escalated up to the transition temperature of N31 laser glass, holding for 3 hours. The designed edgecladding glass, which has been melted and remained at 
$900^{\circ} \mathrm{C}-1100^{\circ} \mathrm{C}$ in another self-made electric Globar furnace prior to casting, will be cast into the heated elliptical or the rectangular cavity mould to bond with the peripheral sideedge of the elliptical glass disk - step 2 in Figure 1. After casting, the higher temperature edge-cladding glass transfers its heat to the elliptical laser glass disk and the steel mould through thermal conduction. Meanwhile, from the exposed surfaces of the edge-cladding glass ring, the laser glass disk and the mould, the heat inside them will be transferred to the ambient environment through radiation and convection. These energy transfers occurring at the high temperature result in a temperature redistribution, and especially a larger temperature gradient over the elliptical laser glass disk. Soinduced thermal stress will even result in a severe cracking for the edge-cladding glass ring and/or laser glass elliptical disk, which will be numerically simulated at high temperature to optimize the casting temperature.

After solidifying, the cladded glass disk will be preliminarily annealed and cooled down within the muffle furnace to room temperature for 2-3 days - step 3 in Figure 1. After demoulding and shaping the rectangular contour into the designed elliptical contour, and other necessary mechanical fabrications, inspections for bubbles at the edge-cladding interface, as well as the tests for residual reflectivity and stress distribution, will be performed. Two light-pass aperture surfaces of the qualified disk will be mechanically processed further and then the disk will be annealed finely within a muffle furnace (Nabertherm, Germany) for about 1 week, with a nearly one-second cooling rate of the preliminary annealing. After fine annealing, step 4 in Figure 1, the residual reflectivity at the cladding interface and the residual stress distribution covering the whole disk are measured again. Finally, the light-pass surfaces of the qualified disk will be processed to test the optical quality required by highpower laser applications - step 5 in Figure 1.

\subsection{Numerical simulation for monolithic edge-cladding}

To simulate the thermal stress distribution over the elliptical Nd-doped phosphate laser glass disk, while it has just been cladded by the monolithic edge-cladding and it is still at high temperature around its glass transition temperature, COMSOL Multiphysics is applied. First, by the Solid Heat Transfer Module of COMSOL, the heat conduction, convection and radiation processes are simulated for an integrated system including the elliptical/rectangular steel mould, the Nd-glass elliptical disk, the edge-cladding glass in the gap between the Nd-glass disk and the applied mould, and the ambient environment. The original temperature distribution over the Nd-glass disk at the transition temperature of $450^{\circ} \mathrm{C}$ must be redistributed due to the high-temperature casting of $900^{\circ} \mathrm{C}-1100^{\circ} \mathrm{C}$ of the edge-cladding glass. Second, by the Solid Mechanics Module of the COMSOL, the thermal expansion interactions among and in the mould, Nd-glass and edge-cladding glass are simulated based on the calculated temperature redistribution by the Solid Heat Transfer Module. These two modules are coupled by the thermal expansion coefficients with temperature, and the mould steel, Nd-glass and the edge-cladding glass are treated as linear elastic materials. Thus, the high-temperature thermal stress distribution, which is the result of the temperature redistribution due to high-temperature casting of the monolithic edge-cladding process, is numerically simulated by COMSOL Multiphysics, a finite element software.

For the finite element simulation, the elliptical ring of the edge-cladding glass and the elliptical disk of the $\mathrm{Nd}$ glass will be meshed by a sweeping method, and hexahedral units will be established. The applied elliptical or rectangular steel mould will be meshed by a free meshing method, and tetrahedral units will be established.

The following simplifications are made in the simulation of the thermal stress distribution at high temperature. (1) Only the mould, the poured molten edge-cladding glass and the elliptical Nd-glass disk are the research objects, without considering the change of furnace temperature. (2) Assume that the molten edge-cladding glass has already been filled quickly into the gap between the mould and the Nd-glass disk at the beginning, which means the temperature change during the casting and the flow is not taken into consideration. (3) The glass phase transitions are ignored. Only the temperature and corresponding volume change are considered in the numerical simulation to characterize the temperature redistribution and the induced thermal stress distribution during the initial cooling process.

When studying the influence of different casting temperatures, the parametric sweep simulation is performed between $700^{\circ} \mathrm{C}$ and $1200^{\circ} \mathrm{C}$, and the interval is set as $100^{\circ} \mathrm{C}$. However, while performing the monolithic edge-cladding experiments under $700^{\circ} \mathrm{C}$ and $800^{\circ} \mathrm{C}$, it is found out that the viscosity of the edge-cladding glass is too large to perform casting smoothly. In addition, under $1200^{\circ} \mathrm{C}$, it is easy to make the Nd-glass elliptical disk twist or deform. In the following, the simulation results only under $900^{\circ} \mathrm{C}-1100^{\circ} \mathrm{C}$ are shown and discussed.

\subsection{Test methods for monolithic edge-cladding}

The residual stress birefringence distribution is determined by a StrainMatic/M4150.10 stress analyser (Ilis GmbH, Germany), based on the polarized stress birefringence method, that is, the Senarmont phase shifting method. It is equipped with a $592 \mathrm{~nm}$ collimated light-emitting diode (LED) light source, and its test aperture is $105 \mathrm{~mm} \times 105 \mathrm{~mm}$. For the optical retardation, the measurement accuracy is $0.1 \mathrm{~nm}$ and the repeatability is $\pm 0.01 \mathrm{~nm}$.

The bubble distribution on the cladding interface is observed with an industrial digital microscope, a VHX7000 (Keyence Corporation, Japan), equipping with a 
VH-Z500R/Z500T high-resolution zoom lens of $500 \times$ magnification.

For the residual reflectivity test, isosceles right-angled triangle samples are cut out from the monolithic edge-cladded slabs, in which the cladding glass is at the hypotenuse of the triangle. The residual reflectivity is calculated based on the determined laser intensities of the incident and the reflected light. The applied laser is a $1053 \mathrm{~nm} \mathrm{Nd:YLF} \mathrm{laser}$ (Beamtech Optronics Co., Ltd., China), whose repetition frequency is $10 \mathrm{~Hz}$ and pulse energy is $10 \mathrm{~mJ}$. A laser energy meter from LaserStar (Ophir Optronics Solutions Ltd., Israel) with a PD10 sensor, whose lowest measurable energy is $1 \mathrm{~nJ}$, is used to determine the incident and reflected laser pulse energy.

The wavefront of the edge-cladded elliptical disk after optical precision fabrication, which is Brewster's angle placed, is determined by a Fizeau-type interferometer, GPI XP/D (Zygo, USA), equipped with a frequency-stabilized $\mathrm{He}-\mathrm{Ne}$ laser at the wavelength of $632.8 \mathrm{~nm}$.

\section{Results and discussion}

\subsection{Thermal stress distribution due to monolithic edge- cladding}

With regard to the stress specification of the N31 elliptical laser glass disk cladded by the monolithic edge-cladding process, we refer to BS ISO 10110-2:1996 $6^{[27]}$, Optics and Optical Instruments - Preparation of Drawings for Optical Elements and Systems - Part 2: Material Imperfections - Stress Birefringence, which was implemented for the National Ignition Facility ${ }^{[28]}$. According to Refs. [27,28], the maximum optical retardation for the final product of the cladded N31 elliptical laser glass disk is less than or equal to $5 \mathrm{~nm} / \mathrm{cm}$, as determined by stress birefringence. To realize this requirement, a 1 -week fine annealing is always needed to reduce the residual stress, which will be discussed in Section 3.4. However, before that fine annealing, the most important thing is to avoid breaking and cracking the elliptical Nd-glass disk and the edge-cladding glass ring during the monolithic edgecladding process. In this section, the casting temperature, which is the key parameter for the riskiest casting process during the monolithic edge-cladding, is discussed on the basis of the numerical simulations as well as the practical experiments.

According to previous experience, the thermal stress generated during the high-temperature melt bonding process by the monolithic edge-cladding is mainly concentrated close to the interface region between the edge-cladding glass and the laser glass. In the process of continuous casting, the elliptical laser glass disk is still in the state of solid around the glass transition temperature of $450^{\circ} \mathrm{C}$. However, after being cast, the molten edge-cladding glass previously with the initial temperature of $900^{\circ} \mathrm{C}-1100^{\circ} \mathrm{C}$ will be cooled very quickly

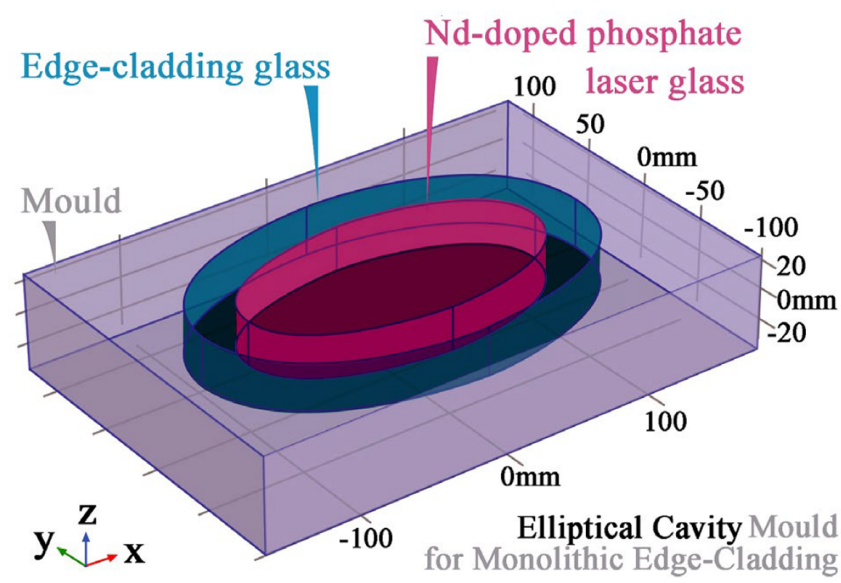

(a) casting into elliptical mould cavity

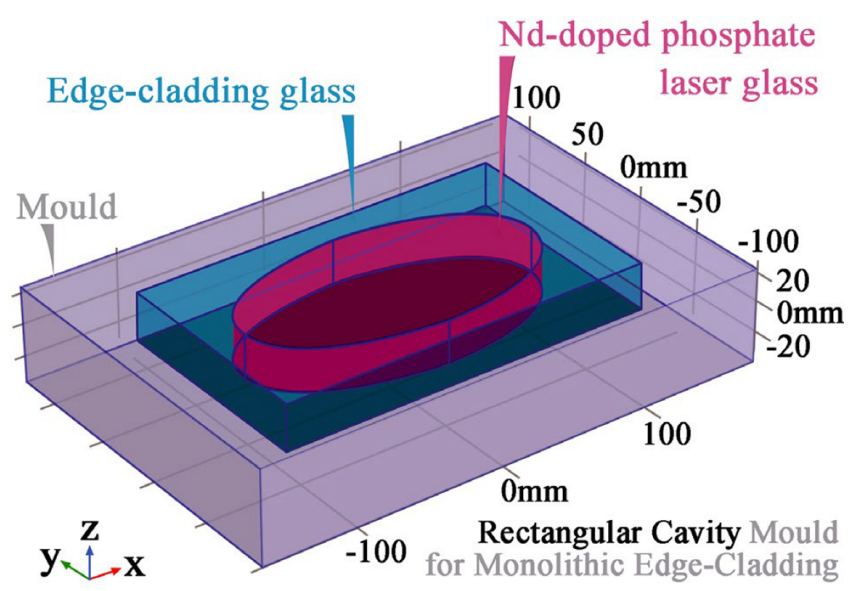

(b) casting into rectangular mould cavity

Figure 2. Monolithic edge-cladding process by using (a) an elliptical cavity mould or (b) rectangular cavity mould, both for the same elliptical disks of N31-type Nd-doped laser glass, respectively installed in the elliptical or rectangular mould cavity.

from the melt state to the solid state in the interface region, and the volume shrinks greatly with decreasing temperature. Thus, a very strong compressive stress ${ }^{[29]}$ must be generated in the interface region between the edge-cladding glass and the laser glass. On the other hand, even if the edge-cladding glass has been solidified and cooled for some time, its temperature is still higher than that of the laser glass. Such a temperature gradient existing from the outer edge-cladding layer to the inner laser glass disk can produce a severe thermal stress ${ }^{[30]}$ distribution over the whole disk at high temperature. These stresses induced by the high-temperature casting during the monolithic edge-cladding will most probably break and/or crack the glasses if large enough, which will be numerically simulated by COMSOL Multiphysics.

In the simulations as well as the experiments, either elliptical or rectangular cavity moulds could be used to clad the elliptical laser glass disk by the monolithic edge-cladding process, as shown in Figure 2. The elliptical laser glass 


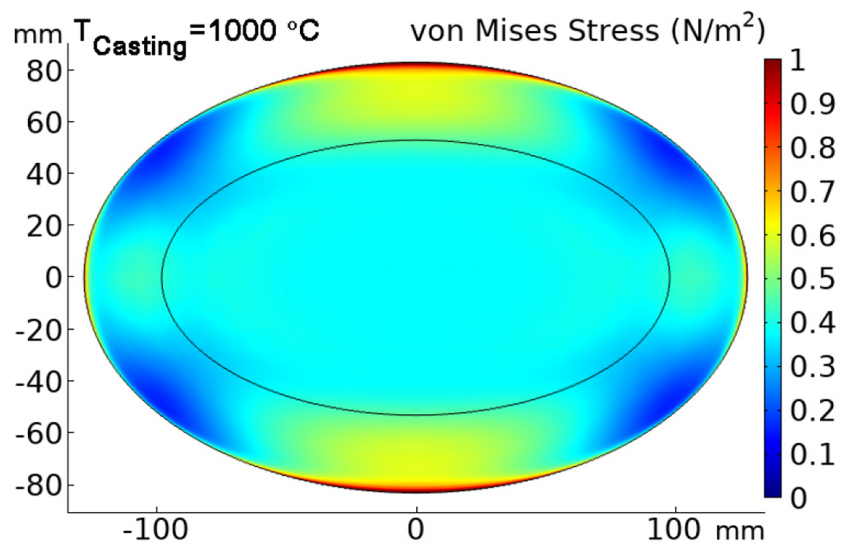

(a) $1000{ }^{\circ} \mathrm{C}$ casting into elliptical mould cavity

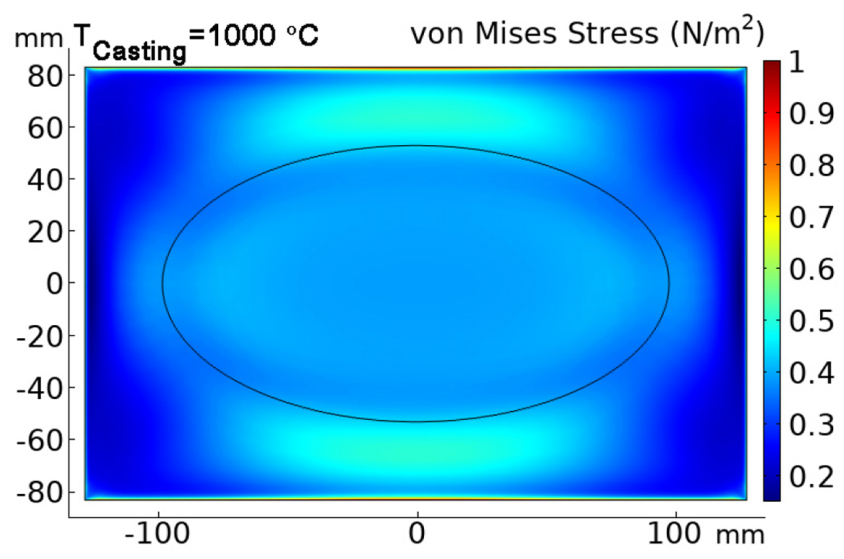

(b) $1000{ }^{\circ} \mathrm{C}$ casting into rectangular mould cavity

Figure 3. Numerically simulated thermal stress distribution over the N31 elliptical disk cladded in the (a) elliptical mould cavity or (b) rectangular mould cavity, when the casting temperature is $1000^{\circ} \mathrm{C}$. The external (a) elliptical and (b) rectangular lines draw the contour of the applied mould cavities. The inner elliptical lines in (a) and (b) depict the N31 elliptical laser glass disk. Between these two lines, there is the edge-cladding glass.

disk, whose size is set to be $194 \mathrm{~mm}$ of the major axis and $102 \mathrm{~mm}$ of the minor axis, is always placed in the centre of the elliptical or rectangular mould cavity. For the elliptical mould cavity, the major axis is $256 \mathrm{~mm}$ and the minor axis is $166 \mathrm{~mm}$, as shown in Figure 2(a). For the rectangular mould cavity, the long side is $256 \mathrm{~mm}$ and the short side is $166 \mathrm{~mm}$, as shown in Figure 2(b). The melted edge-cladding glass will be cast into the $31-32 \mathrm{~mm}$ width gap between the mould cavity and the elliptical disk. No matter whether using the elliptical or the rectangular cavity mould, the cladded elliptical disks with the size of $200 \mathrm{~mm}$ of the major axis and $108 \mathrm{~mm}$ of the minor axis will be fabricated mechanically and optically for the stress birefringence measurement.

Before optimizing the casting temperature, the applied mould should be optimized firstly. Figures 3(a) and 3(b) show the simulated thermal stress distribution over the glass disk, respectively cladded in the elliptical and rectangular cavity moulds by monolithic edge-cladding. Except for the different cavity moulds used, all of the other edgecladding conditions, including the $1000^{\circ} \mathrm{C}$ casting temperature, remain the same. The maximum and average von Mises stresses are 1.27 and $0.57 \mathrm{~N} / \mathrm{m}^{2}$ if using the elliptical cavity mould, but only 1.02 and $0.37 \mathrm{~N} / \mathrm{m}^{2}$ if using the rectangular cavity mould. Regarding the risk to break or crack the edgecladding glass and the laser glass, the region of stress concentration is of concern. As shown in Figure 3(a), with the elliptical cavity mould the width for the stress concentrated region with the stress around $1 \mathrm{~N} / \mathrm{m}^{2}$ (red region) is larger than $5 \mathrm{~mm}$. However, as shown in Figure 3(b) with the rectangular cavity mould, the width is smaller than $0.5 \mathrm{~mm}$. If using the elliptical cavity mould, the edge-cladding glass in the region close to the side of the cavity would be cracked or broken more easily. On the other hand, along the direction of the minor axis of the laser glass disk, there exists a second stress concentrated region in the gap between the mould cavity and the laser glass. As shown in Figure 3(a), with the elliptical cavity mould, there appears to be stress higher than $0.6 \mathrm{~N} / \mathrm{m}^{2}$ in such a region. However, as shown in Figure 3(b), with the rectangular cavity mould, there appears to be stress lower than $0.5 \mathrm{~N} / \mathrm{m}^{2}$ in the same region. If using the elliptical cavity mould, the laser glass along the minor axis of itself and close to the edge-cladding glass would be cracked or broken easily. The simulation shows that the monolithic edge-cladding process should apply the rectangular cavity mould, rather than the elliptical cavity mould, to achieve a successful edge-cladding almost without breaking and/or cracking.

The next step is to optimize the casting temperature during the monolithic edge-cladding process. By using the same rectangular cavity mould, the thermal stress distributions are simulated for different casting temperatures of $900^{\circ} \mathrm{C}$, $1000^{\circ} \mathrm{C}$ and $1100^{\circ} \mathrm{C}$, as shown in Figures $4(\mathrm{a}), 3(\mathrm{~b})$ and $4(\mathrm{~b})$, respectively. The maximum (or minimum) von Mises stress is increased from $1.02\left(0.14 \mathrm{~N} / \mathrm{m}^{2}\right)$ to $1.03 \mathrm{~N} / \mathrm{m}^{2}\left(0.16 \mathrm{~N} / \mathrm{m}^{2}\right)$ with the increasing casting temperature. If only using the maximum at the casting temperatures of $900^{\circ} \mathrm{C}$ and $1000^{\circ} \mathrm{C}$, there is almost no increase. However, the average von Mises stress is increased from $0.34\left(900^{\circ} \mathrm{C}\right)$ to $0.39 \mathrm{~N} / \mathrm{m}^{2}\left(1100^{\circ} \mathrm{C}\right)$. On the other hand, for $1100^{\circ} \mathrm{C}$, there appears to be stress higher than $0.6 \mathrm{~N} / \mathrm{m}^{2}$ in the region, located in the edgecladding glass close to the end of the minor axis of the laser glass disk, as shown in Figure 4(b). Such a von Mises stress is as high as that with the elliptical cavity mould, as shown in Figure 3(a). If using $1100^{\circ} \mathrm{C}$ casting temperature for the rectangular cavity mould, there also exists the risk to break and crack the glasses. If using $900^{\circ} \mathrm{C}$ and $1000^{\circ} \mathrm{C}$ casting temperatures for the rectangular cavity mould, there only appears to be stress lower than $0.5 \mathrm{~N} / \mathrm{m}^{2}$, as shown in the upper and lower parts of Figures 4(a) and 3(b). The simulation means the rectangular cavity mould and the 


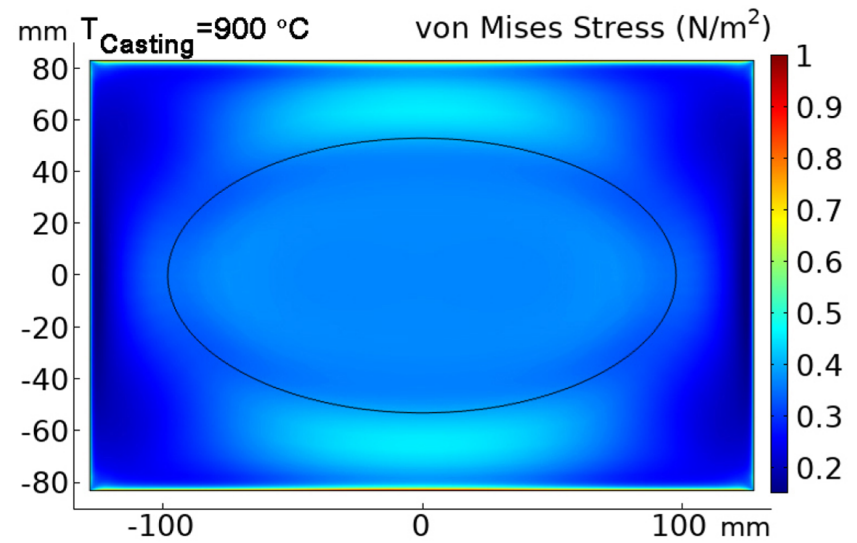

(a) $900{ }^{\circ} \mathrm{C}$ casting into rectangular mould cavity

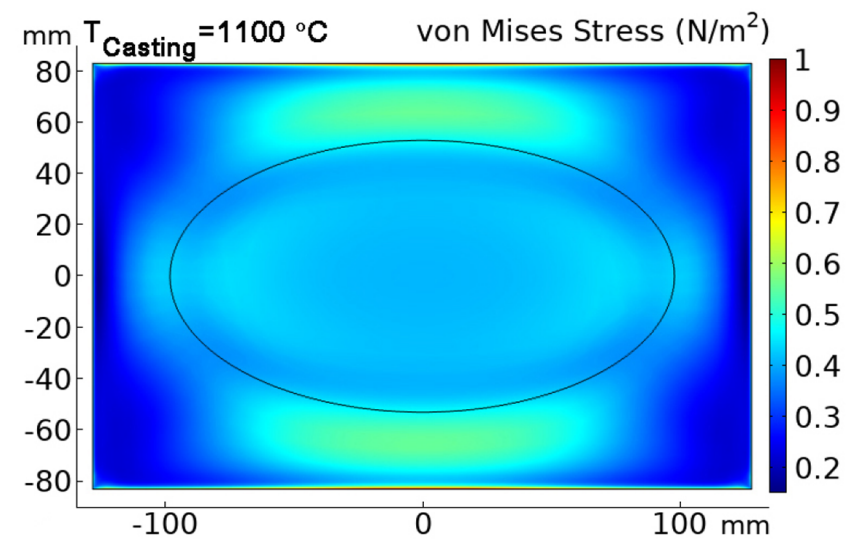

(b) $1100{ }^{\circ} \mathrm{C}$ casting into rectangular mould cavity

Figure 4. Numerically simulated thermal stress distribution over the N31 elliptical disk cladded in a rectangular mould cavity, when the casting temperature is (a) $900^{\circ} \mathrm{C}$ or (b) $1100^{\circ} \mathrm{C}$. The external rectangular lines in (a) and (b) draw the contour of the applied mould cavity. The inner elliptical lines in (a) and (b) depict the N31 elliptical laser glass disk. Between these two lines, there is the edge-cladding glass.

casting temperatures of $900^{\circ} \mathrm{C}$ and $1000^{\circ} \mathrm{C}$ would be the better choice for the monolithic edge-cladding process.

To confirm the numerical optimization for the thermal stress due to different temperature casting, practical experimental processes are carried out at different casting temperatures, but using the same rectangular cavity mould, the same edge-cladding glass and the same-sized N31 phosphate laser glass disks with the maximum optical retardation lower than $5 \mathrm{~nm} / \mathrm{cm}^{[27,28]}$. After the high-temperature melt casting and bonding, step 2 in Figure 1, the cladded disks will undergo the same preliminary annealing and mechanical fabrication - step 3 in Figure 1. At this time, the cladded Ndglass elliptical disk with the same size and edge-cladding thickness can be used for the determination of the stress birefringence distribution, as shown in Figures 5(a)-5(c), respectively corresponding to the casting temperatures of $900^{\circ} \mathrm{C}, 1000^{\circ} \mathrm{C}$ and $1100^{\circ} \mathrm{C}$. It should be pointed out that the

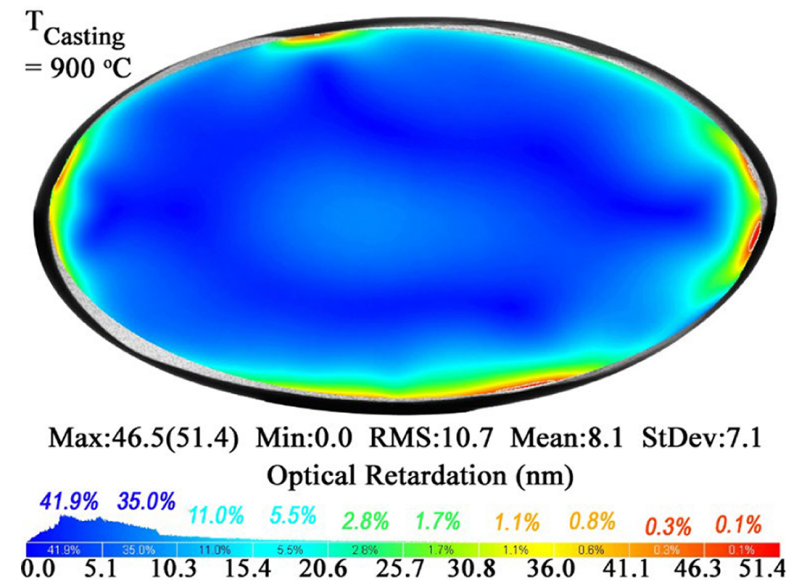

(a) by casting temperature of $900{ }^{\circ} \mathrm{C}$

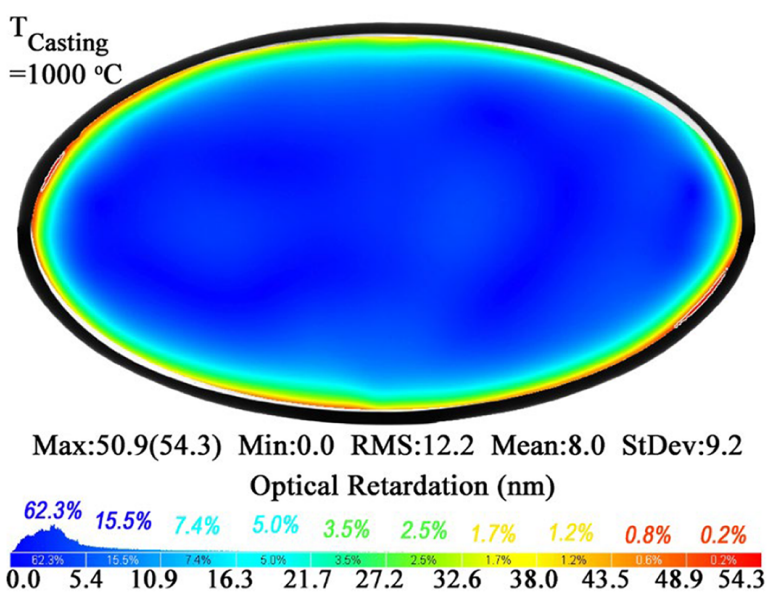

(b) by casting temperature of $1000{ }^{\circ} \mathrm{C}$

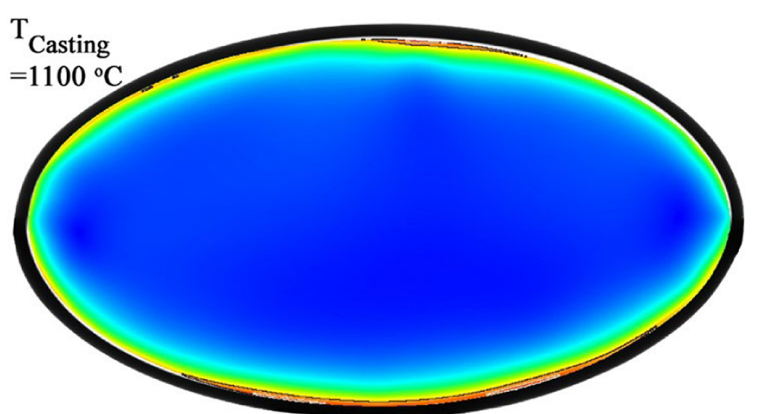

Max:87.8(97.2) Min:0.1 RMS:23.6 Mean:16.3 StDev:17.1 Optical Retardation (nm)

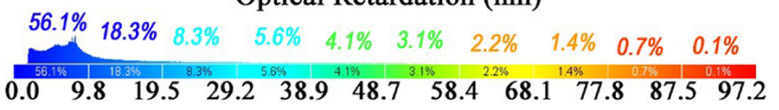

(c) by casting temperature of $1100{ }^{\circ} \mathrm{C}$

Figure 5. Determined 2D stress birefringence distributions over the N31 elliptical disk cladded in the rectangular cavity mould, when the casting temperature is at (a) $900^{\circ} \mathrm{C}$, (b) $1000^{\circ} \mathrm{C}$ and (c) $1100^{\circ} \mathrm{C}$, respectively. The contour of the N31 elliptical laser glass disk is outlined by a black bold line. Below each 2D stress distribution pattern, the statistical results for the determined point-to-point stresses over the disk are shown, including the maximum, minimal, root mean square, mean and standard deviation values, as well as the percentage distribution with the corresponding optical retardation indicated by the colour bar. 
determined stress birefringence distribution in Figure 5 is the result of all kinds of comprehensive factors, such as hightemperature casting, preliminary annealing, and mechanical fabrication ${ }^{[29]}$. After the mechanical fabrication of step 3 in Figure 1, a 1-week fine annealing will be carried out to achieve the stress specification, the maximum optical retardation of less than or equal to $5 \mathrm{~nm} / \mathrm{cm}^{[27,28]}$, which will be discussed in Section 3.4.

From Figures 5(a)-5(c), the maximum optical retardation is increased from $46.5 \mathrm{~nm}(11.6 \mathrm{~nm} / \mathrm{cm})$ for $900^{\circ} \mathrm{C}$ casting temperature to $50.9 \mathrm{~nm}(12.7 \mathrm{~nm} / \mathrm{cm})$ for $1000^{\circ} \mathrm{C}$, and to $87.8 \mathrm{~nm}(22.0 \mathrm{~nm} / \mathrm{cm})$ for $1100^{\circ} \mathrm{C}$. Although they cannot satisfy the stress specification of less than or equal to $5 \mathrm{~nm} / \mathrm{cm}^{[27,28]}$, a smaller stress level with an even stress distribution is an ideal foundation for the fine annealing process. While using $1100^{\circ} \mathrm{C}$ casting temperature, the maximum and mean optical retardations are $87.8(22.0 \mathrm{~nm} / \mathrm{cm})$ and $16.3 \mathrm{~nm}(4.1 \mathrm{~nm} / \mathrm{cm})$, which are 1.9 and 2.1 times of using $900^{\circ} \mathrm{C}$. Even if edge-cladding can take place at this casting temperature, it is difficult to achieve the specification of less than or equal to $5 \mathrm{~nm} / \mathrm{cm}^{[27,28]}$ during the fine annealing. As for the casting temperatures of $900^{\circ} \mathrm{C}$ and $1000^{\circ} \mathrm{C}$, the maximum and mean optical retardations are $46.5(11.6 \mathrm{~nm} / \mathrm{cm})$ and $8.0 \mathrm{~nm}$ $(2.0 \mathrm{~nm} / \mathrm{cm})$ for $900^{\circ} \mathrm{C}$, and $50.9(12.7 \mathrm{~nm} / \mathrm{cm})$ and $8.1 \mathrm{~nm}$ $(2.0 \mathrm{~nm} / \mathrm{cm})$ for $1000^{\circ} \mathrm{C}$. Such an equal stress level implies that the casting temperatures of both $900^{\circ} \mathrm{C}$ and $1000^{\circ} \mathrm{C}$ would be the better choice, similar to the above simulation analysis. While it can be seen from the bottom of Figure 5(a) for $900^{\circ} \mathrm{C}$ that the statistics illustrate that there are only $41.9 \%$ stress points with the optical retardation of $0-5.1 \mathrm{~nm}$, for $1000^{\circ} \mathrm{C}$, as shown in Figure 5(b), there are $62.3 \%$ stress points with the optical retardation of $0-5.4 \mathrm{~nm}$. This comparison actually reflects that, if using the casting temperature of $1000^{\circ} \mathrm{C}$ rather than $900^{\circ} \mathrm{C}$, there should be a larger region distributed with a lower stress. This must be a favourable base for the fine annealing process to achieve the stress specification of less than or equal to $5 \mathrm{~nm} / \mathrm{cm}^{[27,28]}$, which will be discussed in Section 3.4.

\subsection{Bubble distribution on the monolithic edge-cladding interface}

The applied casting temperature during the monolithic edgecladding not only affects the thermal stress, but also the bubbles distributed on the edge-cladding interface. As for the delaminations existing with the bubbles, which were observed in the polymerically bonded layer for the edgecladded octagonal Nd-glass disk ${ }^{[31]}$, they are even more harmful to the suppression of the amplified spontaneous emission than the bubbles. By the monolithic edge-cladding process, there is no organic layer between Nd-glass and the edge-cladding glass, and there is no delamination of the polymerically bonded layer. However, it should be noted that there are really subsurface defects generated during the optical cold processing for the side-edge of N31 elliptical Nd-glass disk. The fused silica glass and $\mathrm{Y}_{3} \mathrm{Al}_{5} \mathrm{O}_{12}$ crystal have the least amount of subsurface defect depth, but the phosphate glass has the deepest depth to produce subsurface defects $^{[32]}$. If the subsurface defects are not eliminated, after casting high-temperature edge-cladding glass to clad the side-edge of the Nd-glass disk, the subsurface defect layer must be peeled off from the side-edge of Nd-glass disk. If so, delaminations will be observed in the cladding interface region. Fortunately, these subsurface defects under the side-edge surface, as well as impurities and particles on the surface, can be removed effectively by the buffer solution of the base and the mixed acid solution during the surface treatments ${ }^{[33]}$ - step 1 in Figure 1. Such surface treatments not only can contribute to fully eliminating the delaminations, but also can contribute to efficiently reducing the number of interface bubbles. Thus, the residual interface bubbles become the main scattering defect points at the cladding interface by the monolithic edge-cladding.

Figure 6 shows typical bubble micrographs at the edgecladding interface with different casting temperatures, namely $900^{\circ} \mathrm{C}$ for Figure $6(\mathrm{a}), 1000^{\circ} \mathrm{C}$ for Figure 6(b) and $1100^{\circ} \mathrm{C}$ for Figure $6(\mathrm{c})$. It can be found that many bubbles with different sizes appear at the edge-cladding interface, which are originated from the high-temperature contact between the edge-cladding glass and the side-edge of the laser glass disk during the melt casting and bonding processes.

To understand the mechanism of bubble formation at the cladding interface, three statistics bar charts for $72 \times 3$ observed micrographs are also shown at the bottom of each typical micrograph, respectively. At the $900^{\circ} \mathrm{C}$ casting temperature, the bubble density is as high as $29.2 \mathrm{~mm}^{-2}$ with the maximal total number of bubbles, among which $91.9 \%$ are of sizes smaller than $20 \mu \mathrm{m}$. At $1000^{\circ} \mathrm{C}$, the bubble density is $13.3 \mathrm{~mm}^{-2}$ for all bubbles, among which $84.8 \%$ are of sizes smaller than $20 \mu \mathrm{m}$. At $1100^{\circ} \mathrm{C}$, the bubble density is $9.6 \mathrm{~mm}^{-2}$ for all bubbles, among which $48.1 \%$ are of sizes smaller than $20 \mu \mathrm{m}$. Regarding the bubble density for all bubbles, it decreases with the increasing casting temperature. It should be noted that such a decrease mainly depends on the number decrease for bubbles smaller than $20 \mu \mathrm{m}$. As seen in Figure 6(c), there are fewer small bubbles with the $1100^{\circ} \mathrm{C}$ casting temperature. With the increasing casting temperature, the bonding process with more energy can repair more of the residual defects, such as mechanical scratches, chemical corrosion pits, and environmental particles, which survive or occur after and during the surface treatments ${ }^{[33]}$. As a result, the number of these small bubbles is decreased with the increasing casting temperature.

On the other hand, it can be found out that there are some bubbles with sizes larger than $40 \mu \mathrm{m}$ and smaller than $50 \mu \mathrm{m}$, which are newly generated while using the $1100^{\circ} \mathrm{C}$ 


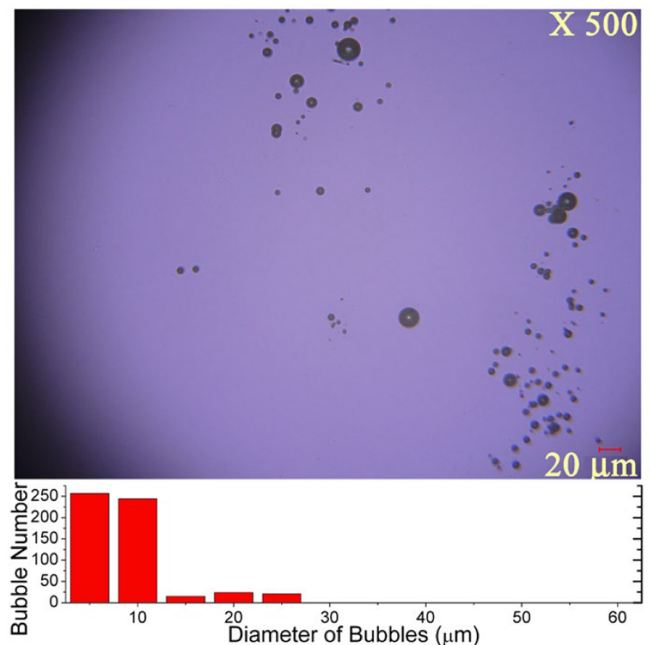

(a) by $900{ }^{\circ} \mathrm{C}$ casting temperature

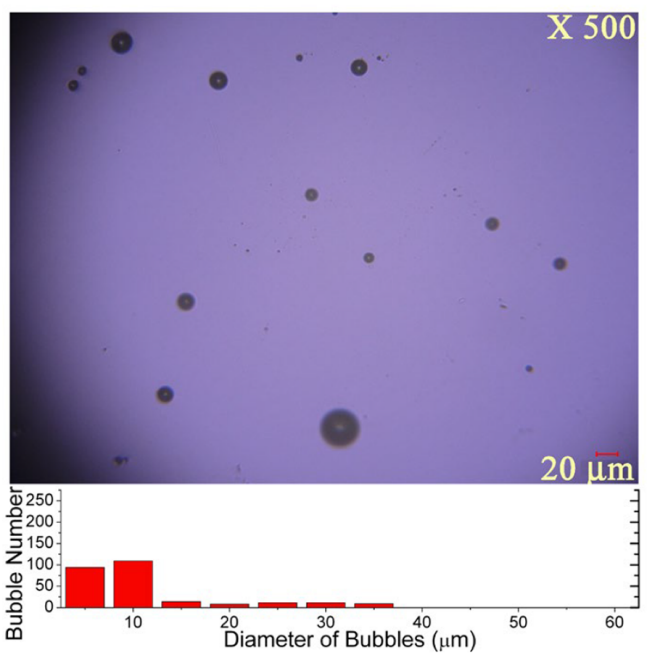

(b) by $1000{ }^{\circ} \mathrm{C}$ casting temperature

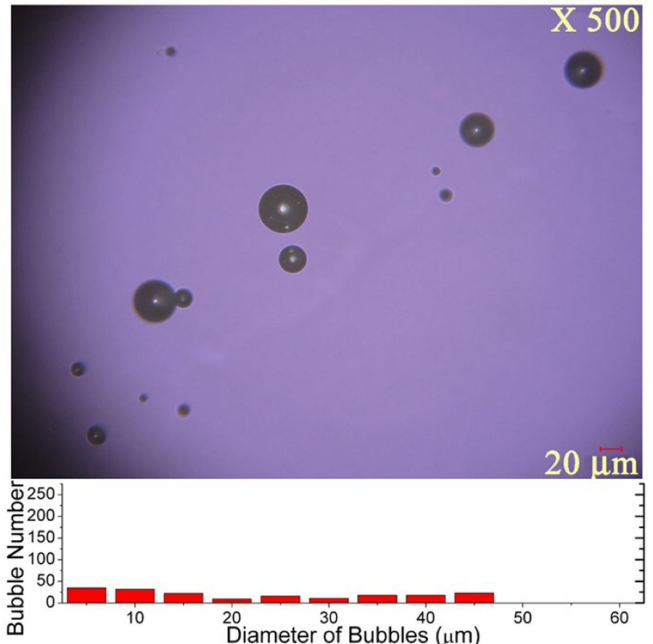

(c) by $1100^{\circ} \mathrm{C}$ casting temperature

Figure 6. Typical bubble distributions on the interface between edgecladding glass and N31 laser glass when the casting temperature is at (a) $900^{\circ} \mathrm{C}$, (b) $1000^{\circ} \mathrm{C}$ and (c) $1100^{\circ} \mathrm{C}$. The statistical bar chart of the observed 72 micrographs for each casting temperature is respectively shown below each typical micrograph. casting temperature, as seen in Figure 6(c). Since these larger bubbles have not been observed in Figures 6(a) and 6(b), $900^{\circ} \mathrm{C}$ and $1000^{\circ} \mathrm{C}$ casting cannot result in these $40-50 \mu \mathrm{m}$ bubbles. However, while using the $1000^{\circ} \mathrm{C}$ casting temperature, there are some $30 \mu \mathrm{m}$ bubbles, as shown in Figure 6(b), which are not observed in Figure $6(\mathrm{a})$ at $900^{\circ} \mathrm{C}$ and also can be observed in Figure 6(c) at $1100^{\circ} \mathrm{C}$. It means there is a second mechanism to generate larger size bubbles with the increasing casting temperature. A higher temperature usually can decrease the viscosity. A lower viscosity makes the smaller bubbles prone to flowing and accumulating, and thus to generating the larger bubbles. During the flow and accumulation period, the surface tension gradient, which should be increased with the casting temperature, produces a driving force on the smaller bubbles and causes them to move towards the solidifying interface ${ }^{[34]}$.

With the increasing casting temperature from $900^{\circ} \mathrm{C}$ to $1100^{\circ} \mathrm{C}$, the number of smaller bubbles is decreased and the number of larger bubbles is increased. According to such a crossing correlation, it is better to apply the casting temperature of $1000^{\circ} \mathrm{C}$. As shown in Figures 6(b), the number for less than or equal to $20 \mu \mathrm{m}$ bubbles is decreased by $58 \%$ compared with that of $900^{\circ} \mathrm{C}$, and the number for more than or equal to $40 \mu \mathrm{m}$ bubbles is still zero. If using $1100^{\circ} \mathrm{C}$, some larger bubbles with the size of more than or equal to $40 \mu \mathrm{m}$ appear, as shown in Figures 6(c), which will increase the residual reflectivity.

\subsection{Residual reflectivity of the monolithic edge-cladding interface}

The residual reflectivity of the cladding interface depends mainly on the bubbles and the delaminations generated during the monolithic edge-cladding process by the optimized edge-cladding glass. If there are still subsurface defects, the equivalent residual reflectivity will be up to $10^{-3}$ even if the effects between the defects are ignored ${ }^{[35]}$. As stated in Section 3.2, the defects can be removed by step 1 in Figure 1, and so there is no delamination at the cladding interface. While the residual reflectivity is increased from $10^{-4}$, the laser gain coefficient is definitely decreased ${ }^{[36]}$. While the reflectivity is at $10^{-5}$, its influence on the amplified spontaneous emission and parasitic oscillation can be neglected ${ }^{[37]}$.

The residual reflectivity distributions relating to the casting temperatures of $900^{\circ} \mathrm{C}, 1000^{\circ} \mathrm{C}$ and $1100^{\circ} \mathrm{C}$ are shown in Figures $7(\mathrm{a})-7(\mathrm{c})$, respectively. For each temperature, four samples cut from the edge-cladded disk are applied to determine the residual reflectivity ${ }^{[38]}$. For each sample, 10 points are chosen randomly for the determination of the residual reflectivity. These 40 data points, no matter whether big or small, are all marked in Figure 7 so as to exhibit the reflectivity distribution. As shown in Figure 7, the residual reflectivities for the casting temperatures of $900^{\circ} \mathrm{C}$, 


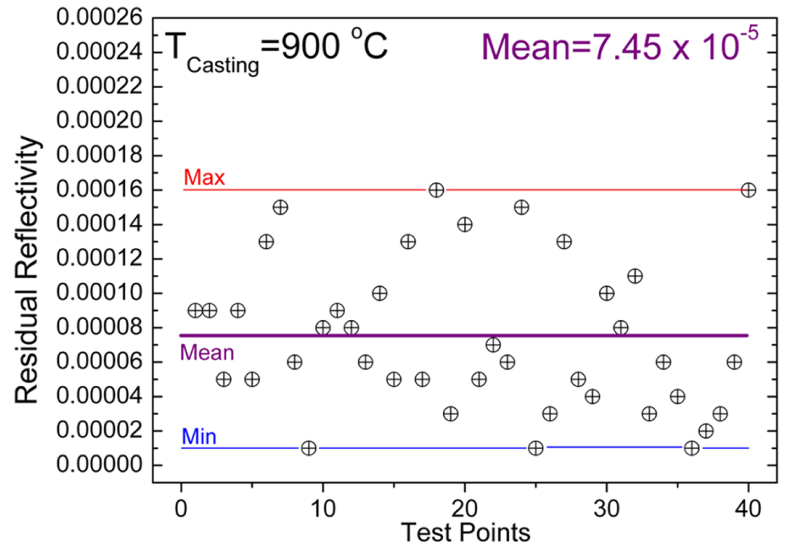

(a) by $900{ }^{\circ} \mathrm{C}$ casting temperature

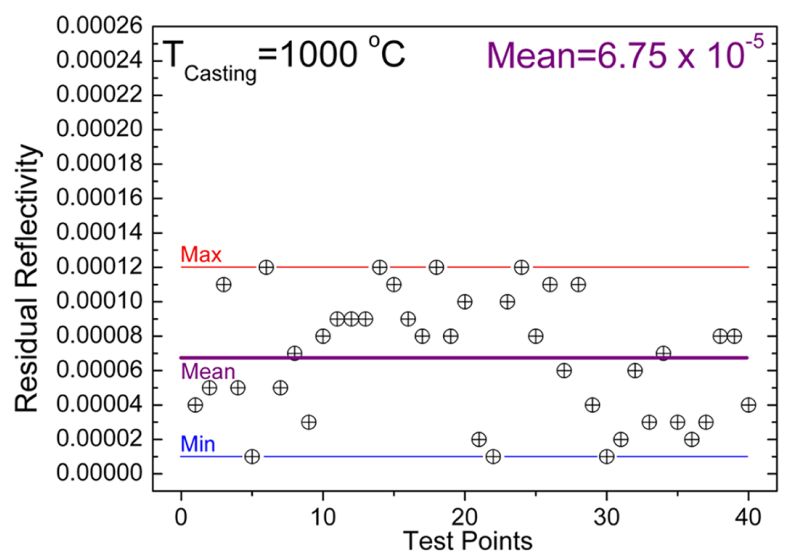

(b) by $1000{ }^{\circ} \mathrm{C}$ casting temperature

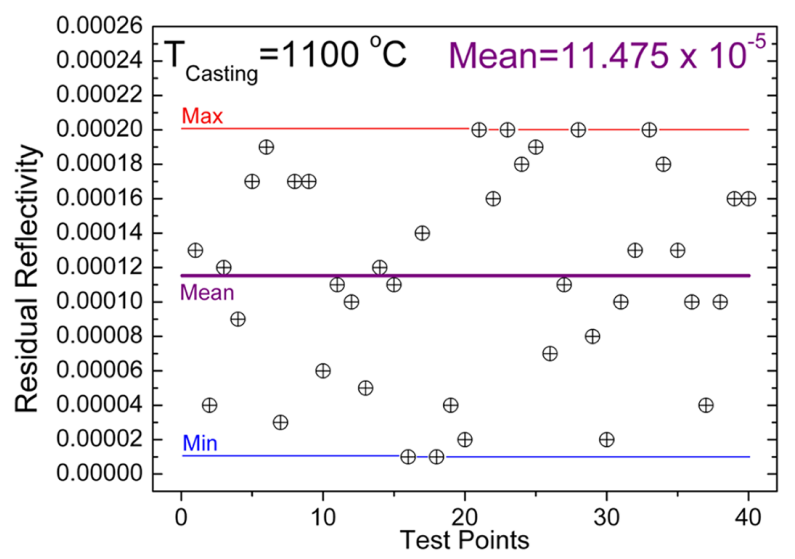

(c) by $1100^{\circ} \mathrm{C}$ casting temperature

Figure 7. Determined residual reflectivity for the cladding interface of the N31 elliptical disk cladded by using different casting temperatures of (a) $900^{\circ} \mathrm{C}$, (b) $1000^{\circ} \mathrm{C}$ and (c) $1100^{\circ} \mathrm{C}$

$1000^{\circ} \mathrm{C}$ and $1100^{\circ} \mathrm{C}$ are distributed in the range of $[0.00001$, $0.00016],[0.00001,0.00012]$ and $[0.00001,0.00020]$, respectively.

When the casting temperature is set at $900^{\circ} \mathrm{C}$, there are many small bubbles with the size of less than or equal to $20 \mu \mathrm{m}$, as shown in Figure 6(a). The reflectivity distribution range between the minimum and maximum is somewhat larger, and the maximum is at $1.6 \times 10^{-4}$, as shown in Figure $7(\mathrm{a})$. When the casting temperature is set at $1100^{\circ} \mathrm{C}$, there are fewer smaller bubbles but more larger bubbles with the size of more than or equal to $40 \mu \mathrm{m}$, as shown in Figure 6(c). The reflectivity distribution range between the minimum and maximum is the largest, and the maximum is up to $2 \times 10^{-4}$, as shown in Figure 7(c). It is better to apply a $1000^{\circ} \mathrm{C}$ casting temperature to achieve a lower residual reflectivity. In this case, there are still no larger bubbles appearing at the cladding interface, as shown in Figure 6(b), and the number of small bubbles is decreased by $58 \%$ comparing with that of $900^{\circ} \mathrm{C}$. The reflectivity distribution range is the smallest, and the maximum is as small as $1.2 \times 10^{-4}$, as shown in Figure 7(b). In particular, the mean reflectivity is $6.75 \times 10^{-5}$, not only smaller than $7.45 \times$ $10^{-5}$ for $900^{\circ} \mathrm{C}$, but also smaller than $11.475 \times 10^{-5}$ for $1100^{\circ} \mathrm{C}$. With the decreasing number of small bubbles from $900^{\circ} \mathrm{C}$ to $1000^{\circ} \mathrm{C}$, the mean reflectivity is only decreased by $10 \%$. However, with the increasing number of large bubbles from $1000^{\circ} \mathrm{C}$ to $1100^{\circ} \mathrm{C}$, the mean reflectivity is increased by $70 \%$. The facts clearly indicate that the residual reflectivity is affected more by the large bubbles. They occupy a larger interface region than small bubbles, which will produce a high reflectivity since the refractive index of bubbles is different from those of the glasses. To reduce the residual reflectivity, the efficient solution is to minimize the total area of the interface bubbles ${ }^{[37]}$. The lower the residual reflectivity, the more design options for the thickness and the absorptivity of the edge-cladding glass that is cladded on the side-edge of the laser glass disk.

\subsection{Fine annealing for monolithic edge-cladded Nd-glass elliptical disk}

The maximum available thickness of the monolithic edgecladding glass ring cladded on the side-edge of Nd-glass disk mainly depends on whether the edge-cladding glass ring breaks during the preliminary annealing - step 3 in Figure 1. It is very important for the yield for the high-temperature monolithic edge-cladding process. If both the edge-cladding glass and Nd-glass do not break or crack, they are demoulded together from the rectangular cavity mould. After demoulding, the outer side of the edge-cladding glass, with the rectangular shape corresponding to the applied rectangular mould cavity, will be cut and milled to the elliptical shape with the chosen thickness. Then, the two aperture surfaces of the cladded Nd-glass elliptical disk will be ground coarsely as the base of the optical polishing - step 5 in Figure 1. As a result, the thermal and mechanical stresses must be generated and remain ${ }^{[39]}$ in the edge-cladded Nd-glass disk, since it has experienced not only the temperature cooling of steps 2 and 3 but also the mechanical fabrication of step 3 . Thus, the fine 
annealing of step 4 should be applied to reduce the residual stress, which is between the preliminary annealing of step 3 and the precision optical polishing of step 5. In view of this process, the monolithic edge-cladding is more similar to the production of optical glass. It always comprises two annealing processes ${ }^{[40]}$, the short-period coarse annealing (just like step 3, this takes 2-3 days) and then the long-period fine annealing (just like step 4, which takes about 1 week). The fine annealing is an additional important tempering process that has to be performed to reduce the residual stress $^{[40]}$.

Three same-sized elliptical Nd-glass disks cladded by the monolithic edge-cladding with the same $1000^{\circ} \mathrm{C}$ casting temperature, as well as with the same preliminary annealing and the same mechanical fabrication, are prepared for fine annealing under different temperatures. Before the fine annealing, the stress behaviours of these three edge-cladded disks are almost the same as those shown in Figure 5(b) for the $1000^{\circ} \mathrm{C}$ casting temperature discussed in Section 3.1. Their mean optical retardation is converged to 2.00$2.15 \mathrm{~nm} / \mathrm{cm}$ and their maximum optical retardation is converged to $10.2-13.3 \mathrm{~nm} / \mathrm{cm}$, which is larger than twice the $5 \mathrm{~nm} / \mathrm{cm}$ for the stress birefringence specification ${ }^{[27,28]}$.

After being finely annealed under $451^{\circ} \mathrm{C}, 488^{\circ} \mathrm{C}$ and $520^{\circ} \mathrm{C}$, the stress birefringence distributions are as shown in Figures $8(\mathrm{a})-8(\mathrm{c})$, respectively. The mean optical retardation ranged from $7.7(1.9 \mathrm{~nm} / \mathrm{cm})$ to $5.2 \mathrm{~nm}(1.3 \mathrm{~nm} / \mathrm{cm})$ and decreased with the increasing annealing temperature, all of which are below the mean values of $2.00-2.15 \mathrm{~nm} / \mathrm{cm}$ before the fine annealing. With $451^{\circ} \mathrm{C}$ annealing, there are $73.7 \%$ stress points with the optical retardation lower than $8.5 \mathrm{~nm}(2.1 \mathrm{~nm} / \mathrm{cm})$, as shown in Figure $8(\mathrm{a})$. With $488^{\circ} \mathrm{C}$ annealing, there are $73.0 \%$ stress points with the optical retardation lower than $7.2 \mathrm{~nm}(1.8 \mathrm{~nm} / \mathrm{cm})$, as shown in Figure 8(b). These data evince the effectiveness of a higher temperature fine annealing. However, the maximum optical retardation after fine annealing at $451^{\circ} \mathrm{C}$ and $488^{\circ} \mathrm{C}$ is still as high as $38.9(9.7 \mathrm{~nm} / \mathrm{cm})$ and $29.1 \mathrm{~nm}(7.3 \mathrm{~nm} / \mathrm{cm})$, respectively. By further increasing the temperature to $520^{\circ} \mathrm{C}$, the maximum optical retardation is finally decreased to $19.2 \mathrm{~nm}(4.8 \mathrm{~nm} / \mathrm{cm})$, as shown in Figure 8(c). Correspondingly, the mean optical retardation is as low as $5.2 \mathrm{~nm}$ $(1.3 \mathrm{~nm} / \mathrm{cm})$, and there are $81.5 \%$ stress points with the optical retardation lower than $6.8 \mathrm{~nm}(1.7 \mathrm{~nm} / \mathrm{cm})$. These data for $520^{\circ} \mathrm{C}$ fine annealing clearly indicate that the residual stress can be less than the stress birefringence specification $^{[27,28]}$ of $5 \mathrm{~nm} / \mathrm{cm}$ over the full aperture of the cladded elliptical disk of N31 Nd-doped phosphate laser glass by the monolithic edge-cladding process.

Apart from the reduction of the residual stress, the fine annealing has a second purpose, that is, homogenization of the glass structure. In addition to the high-temperature casting process discussed in Section 3.1, the cooling history during the fine annealing determines the final property values ${ }^{[41]}$
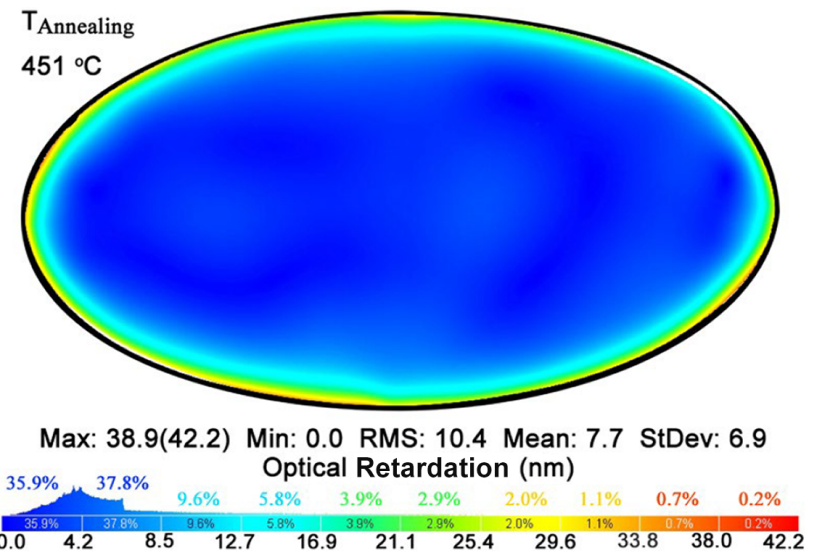

(a) After annealing at $451^{\circ} \mathrm{C}$

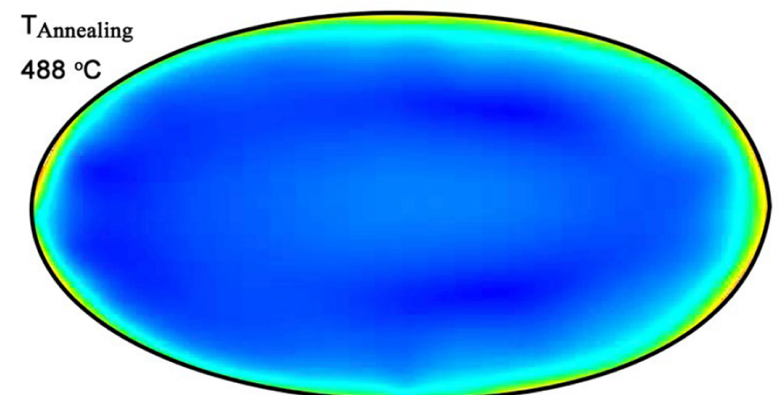

Max: 29.1(40.2) Min: 0.0 RMS: 9.1 Mean: 7.7 StDev: 6.9 Optical Retardation $(\mathrm{nm})$

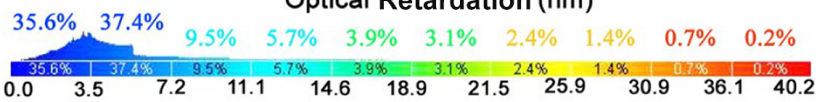

(b) After annealing at $488^{\circ} \mathrm{C}$

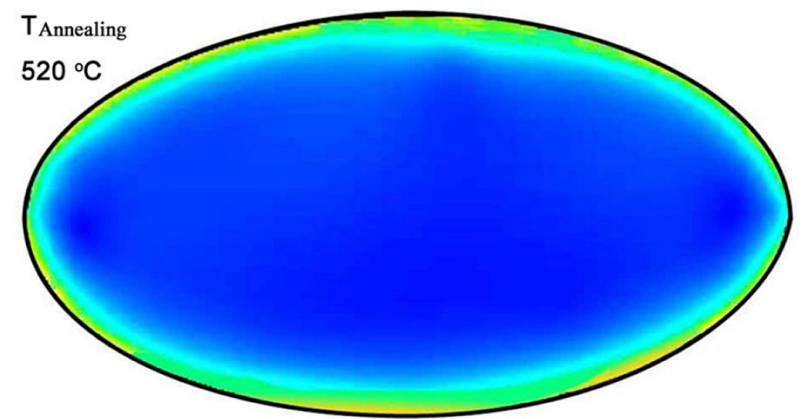

Max: 19.2(22.6) Min: 0.0 RMS: 5.9 Mean: 5.2 StDev: 2.8 Optical Retardation (nm)

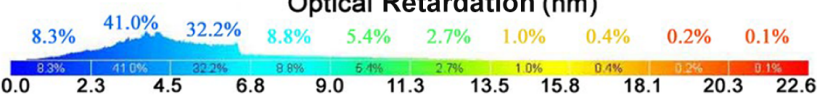

(c) After annealing at $520^{\circ} \mathrm{C}$

Figure 8. Determined 2D stress birefringence distributions over the monolithic edge-cladding N31 elliptical disk after fine annealing. Cladded in a rectangular cavity mould with the casting temperature of $1000^{\circ} \mathrm{C}$, and then 1 week of fine annealing at (a) $451^{\circ} \mathrm{C}$, (b) $488^{\circ} \mathrm{C}$ or (c) $520^{\circ} \mathrm{C}$, respectively. The contour of the N31 elliptical laser glass disk is outlined by a black bold line. Below each 2D stress distribution pattern, the statistical results for the determined point-to-point stresses over the disk are shown, including the maximum, minimal, root mean square, mean and standard deviation values, as well as the percentage distribution with the corresponding optical retardation indicated by the colour bar. 
of the annealed glass, including the optical homogeneity for a given edge-cladded Nd-glass disk. It is also important to satisfy the optical wavefront quality for high-power laser applications, which is specified in terms of the maximum wavefront PV (peak-to-valley) value being less than onethird of the wavelength ${ }^{[42]}$. After step 4 of the fine annealing and step 5 of the precision fabrication, including a mirror polishing for the light-pass aperture surfaces, more than $70 \%$ of the edge-cladded Nd-glass elliptical disks after $520^{\circ} \mathrm{C}$ annealing have achieved this specification, whose maximum PV value of the transmitted wavefront is determined and ranges from 0.222 to 0.313 wavelength $(632.8 \mathrm{~nm}$ for a He$\mathrm{Ne}$ laser). On the other hand, less than $30 \%$ of the edgecladded Nd-glass elliptical disks after $520^{\circ} \mathrm{C}$ annealing have not achieved this specification.

Actually, comparing with $451^{\circ} \mathrm{C}$ and $488^{\circ} \mathrm{C}$ fine annealing, the cooling rate for $520^{\circ} \mathrm{C}$ annealing is increased by $30 \%-$ $60 \%$ because all of these temperatures are set to be cooled down within the same period. A lower cooling rate is beneficial to produce a smaller temperature gradient in the lower thermal conductivity glass, and thus leads to a higher optical homogeneity ${ }^{[43]}$. However, it should be noted that the rearrangement of nearest neighbour configurations in glass becomes less probable for a lower annealing temperature ${ }^{[44]}$. In addition, at the same time, there exists a possible deformation risk at the higher temperature if applying a longtime annealing up to about 15 days for small glass parts or 40 days for large glass parts ${ }^{[45]}$. Unlike high-temperature fine annealing of optical glass, the edge-cladding interface between the edge-cladding glass and Nd-glass would be easily deformed at the high temperature. It is preferred to perform 1 week of annealing at the higher temperature of $520^{\circ} \mathrm{C}$, without decreasing the cooling rate.

Since step 4 of the fine annealing is performed disk by disk, the disk whose PV is above one-third of the wavelength will be treated again by a secondary 1-week fine annealing, just the same as the first one. It not only can save the total fine annealing time, but more importantly puts the edge-cladded disk under an effectively validated temperature control during the 1 week of fine annealing. For the cladded Nd-glass elliptical disk whose wavefront PV was 0.351 wavelength of $632.8 \mathrm{~nm}$ after the first time of fine annealing, it is treated again by the second time fine annealing, and its transmitted wavefront PV is determined to be 0.248 wavelength of $632.8 \mathrm{~nm}$. In this way, its optical homogeneity now can reach the wavefront quality specification of less than onethird of the wavelength ${ }^{[42]}$ for high-power laser applications. This means that the optimized monolithic edge-cladding process can fully satisfy the cladding of the N31 Ndglass elliptical glass disk with a high yield. Figure 9 shows three cladded elliptical disks with the size of $200 \mathrm{~mm} \times 108 \mathrm{~mm} \times 40 \mathrm{~mm}$, in each of which there is a Nd-glass elliptical glass disk with the size of $194 \mathrm{~mm} \times 102 \mathrm{~mm} \times 40 \mathrm{~mm}$. The side-edge of the Nd-glass

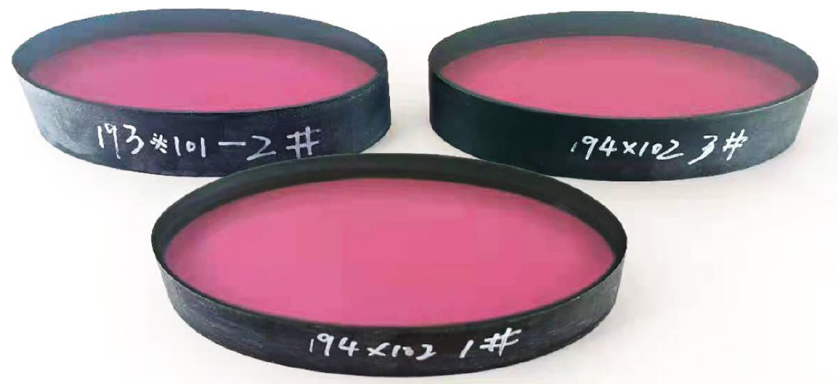

Figure 9. Monolithic edge-cladding N31 elliptical disks with the size of $200 \mathrm{~mm} \times 108 \mathrm{~mm} \times 40 \mathrm{~mm}$. The thickness of the cladding layer can be about 2-20 $\mathrm{mm}$ as designed.

disk can be edge-cladded by a designed $2-20 \mathrm{~mm}$ thick edge-cladding glass ring with a designed $\mathrm{Cu}$-doping concentration, which can be utilized for absorbing $1053 \mathrm{~nm}$ amplified spontaneous emission and parasitic oscillation. If of the same size, comparing with that of the $\mathrm{N} 21 \mathrm{Nd}$-glass elliptical disk cladded by the sealing edge-cladding process, the laser amplifying gain of the N31 Nd-glass elliptical disk cladded by the monolithic edge-cladding process can be increased by about one-third, which is of great significance for high-power laser systems.

\section{Conclusion}

The thermal stress generated during the high-temperature melt casting and bonding processes by the monolithic edgecladding is numerically simulated and experimentally verified. It is indicated that the thermal stress can be decreased if using a rectangular cavity mould instead of an elliptical cavity mould under the same casting temperature of $1000^{\circ} \mathrm{C}$, and with the increasing casting temperature from $900^{\circ} \mathrm{C}$ to $1100^{\circ} \mathrm{C}$ the thermal stress will be increased for the same rectangular cavity mould. Besides the thermal stress, it is also found that the number of smaller bubbles distributed over the monolithic edge-cladding interface is decreased, but the number of larger interface bubbles is increased, and the bubble-affected residual reflectivity is firstly decreased and then increased with the increasing casting temperature. Accordingly, the casting temperature, one of the most important monolithic edge-cladding process parameters, is optimized to be around $1000^{\circ} \mathrm{C}$, which results in better performances for the stress birefringence and the number and size of the edge-cladding interface bubbles, as well as the interface residual reflectivity. After high-temperature casting, bonding and the preliminary annealing, the edgecladded elliptical disks are successfully finely annealed by the monolithic edge-cladding at $451^{\circ} \mathrm{C}, 488^{\circ} \mathrm{C}$ and $520^{\circ} \mathrm{C}$, respectively, in which the higher annealing temperature of $520^{\circ} \mathrm{C}$ can further improve the residual stress and optical homogeneity over the whole disk. So, the annealed edgecladding elliptical N31 phosphate laser glass disk with the 
size of $200 \mathrm{~mm} \times 108 \mathrm{~mm} \times 40 \mathrm{~mm}$ can satisfy the stress birefringence specification of less than $5 \mathrm{~nm} / \mathrm{cm}$ and the wavefront specification of less than one-third of the wavelength. It is now expected that the qualified glass disk edgecladded by the optimized monolithic edge-cladding process can be utilized under a strong liquid cooling condition to pursue a higher laser shot rate for high-power laser systems by using such a higher gain Nd-glass of N31.

\section{Acknowledgements}

The research work was financially supported by the Nd-glass project from National Major Science and Technology Project of China (No. G-GFZX0205010202.1) and the Shanghai International Science \& Technology Cooperation Program (No. 18590712900).

\section{References}

1. C. Goren, Y. Tzuk, G. Marcus, and S. Pearl, IEEE J. Quantum Electron. 42, 1239 (2006).

2. E. I. Moses, T. D. de la Rubia, E. Storm, J. F. Latkowski, J. C. Farmer, R. P. Abbott, K. J. Kramer, P. F. Peterson, H. F. Shaw, and R. F. Lehman, Fusion Technol. 56, 547 (2017).

3. W. Li, Z. Gan, L. Yu, C. Wang, Y. Liu, Z. Guo, L. Xu, M. Xu, Y. Hang, Y. Xu, J. Wang, P. Huang, H. Cao, B. Yao, X. Zhang, L. Chen, Y. Tang, S. Li, X. Liu, S. Li, M. He, D. Yin, X. Liang, Y. Leng, R. Li, and Z. Xu, Opt. Lett. 43, 5681 (2018).

4. J. A. Glaze, S. Guch, and J. B. Trenhome, Appl. Opt. 13, 2808 (1974).

5. S. J. Guch, Appl. Opt. 15, 1453 (1976).

6. A. J. Marker III and K. H. Mader, Proc. SPIE 362, 107 (1983).

7. Y. Asahara and T. Izumitani, US Patent 3885974 (1975).

8. H. Toratani, US Patent 4217382 (1980).

9. J. M. Alexander and H. C. John, US Patent 5718979 (1998).

10. Y. Zhang, X. Wei, M. Li, J. Zheng, J. Zhang, N. Xie, Z. Wang, M. Wang, X. Yan, and X. Jiang, Laser Phys. 23, 055802 (2013).

11. Y. Zhang, H. Ye, M. Li, J. Zheng, X. Wei, S. Gao, Q. Deng, X. Jiang, X. Yan, and Z. Wang, Laser Phys. 23, 075802 (2013).

12. B. Wang, H. Y. Li, H. Xiong, and J. Zhu, in Conference on Lasers and Electro-Optics (CLEO) (2017), paper JW2A-86.

13. S. W. Heinemann, S. Kaierle, S. Zhou, Y. Zhang, Y. Li, H. Xiong, H. Li, J. Zhu, and B. Wang, Proc SPIE 10525, $105250 \mathrm{G}$ (2018).

14. T. H. Powell, M. O. Riley, C. R. Wolfe, R. E. Lyon, J. H. Compell, E. S. Jessop, and J. E. Murray, US Patent 4849036 (1989).

15. L. A. Hackel, T. F. Soules, S. N. Fochs, M. D. Rotter, and S. A. Letts, US Patent 0254536A1 (2005).

16. T. Meng, J. Tang, J. Hu, L. Wen, L. Chen, W. Chen, and L. Hu, China Patent 201010273819.7 (2011).

17. J. H. Campbell and T. I. Suratwala, J. Non-Crys. Solids 318, $263(2000)$.

18. L. Hu, S. Chen, J. Tang, B. Wang, T. Meng, W. Chen, L. Wen, J. Hu, S. Li, Y. Xu, Y. Jiang, J. Zhang, and Z. Jiang, High Power Laser Sci. Eng. 2, e1 (2014).

19. E. I. Moses, J. Atherton, L. Lagin, D. Larson, C. Keane, B. Macgowan, R. Patterson, M. Spaeth, W. B. Van, P. Wegner, and R. Kauffman, J. Phys. Conf. Ser. 688, 012073 (2016).
20. M. Nicolaizeau and J. L. Miquel, Proc. SPIE 10898, 1089802 (2019).

21. W. Zheng, X. Wei, Q. Zhu, F. Jing, D. Hu, J. Su, K. Zheng, X. Yuan, H. Zhou, W. Dai, W. Zhou, F. Wang, D. Xu, X. Xie, B. Feng, Z. Peng, L. Guo, Y. Chen, X. Zhang, L. Liu, D. Lin, Z. Dang, Y. Xiang, and X. Deng, High Power Laser Sci. Eng. 4, e21 (2014).

22. E. Gaul, G. Chériaux, R. Antipenkov, F. Batysta, T. Borger, G. Friedman, J. T. Greene, D. Hammond, J. Heisler, D. Hidinger, A. Jochmann, M. Kepler, A. Kissinger, D. Kramer, J. C. Lagron, A. Meadows, B. Rus, P. Trojek, S. Vyhlídka, and T. Ditmire, in Conference on Lasers and Electro-Optics (CLEO) (2018), paper STu3M.2.

23. B. Wang, Y. Li, P. Zhang, L. Wang, Q. Liu, H. Zhu, A. Guo, Y. Zhang, X. Zhang, Q. Zhou, S. Zhou, J. Zhu, W. Ma, B. Zhu, and J. Zhu, Chin. J. Lasers 46, 1001007 (2019).

24. R. Chonion, J. M. Sajer, E. Bordenave, P. F. Le, P. M. Dalbies, and J. Neauport, Opt. Express 28, 20162 (2020).

25. P. M. Dalbiès, N. Blanchot, E. Bordenave, B. Cadilhon, S. Cavaro, R. Chonion, E. Lavastre, F. P. Le, J. F. Lupi, P. Manac'h, Y. Modin, G. Paquignon, J. M. Sajer, and J. Neauport, in Advanced Solid State Lasers (2020), paper AW1A.5.

26. S. He, Y. Chen, H. Yu, D. Yang, W. Zheng, and X. Zhang, in Pacific Rim Conference on Lasers \& Electro-Optics (2005), p. 818.

27. ISO 10110-2:1996, Optics and Optical Instruments - Preparation of Drawings for Optical Elements and Systems - Part 2: Material Imperfections - Stress Birefringence (1996).

28. D. Y. H. Wang, J. R. E. English, and D. M. Aikens, Proc. SPIE 3782, 7 (1999).

29. L. Zhang and W. Liu, Front. Mech. Eng. 12, 3 (2017).

30. Y. Chen, B. Chen, and M. Bass, Appl. Phys. B 81, 75 (2005).

31. G. J. Quarles, M. J. Shoup, S. D. Jacobs, J. H. Kelly, C. T. Cotton, S. F. Morse, and S. A. Kumpan, Proc. SPIE 1627, 192 (1992).

32. T. I. Suratwala, W. A. Steele, L. A. Wong, and G. C. Tham, Opt. Eng. 58, 092604 (2019).

33. H. Chen, D. He, L. Hu, S. Li, and J. Cheng, Chin. J. Lasers 37, 2035 (2010).

34. Z. Wang, K. Mukai, and I. J. Lee, ISIJ Int. 39, 553 (1999).

35. B. Wang, J. Zhang, S. Shi, K. You, and J. Zhu, High Power Laser Sci. Eng. 4, e9 (2016).

36. C. Tang, S. Chen, X. Tang, B. Wang, J. Zhang, Y. Zhang, L. Wang, and J. Zhu, Proc. SPIE 9255, 92550J (2015).

37. S. E. Stokowski, S. M. Yarema, and I. F. Stowers, Laser Program Annual Report (1980).

38. S. Hirota and T. Izumitani, Appl. Opt. 18, 97 (1979).

39. Y. Ma, N. Wu, H. Zhang, S. Zhang, and L. Zheng, Int. J. Heat Mass Transfer 72, 411 (2014).

40. R. G. Bingham, P. Hartmann, D. D. Walker, H. F. Morian, and R. Jedamzik, Proc. SPIE 4411, 6 (2002).

41. E. Atad-Ettedgui, T. Doehring, S. D’Odorico, P. Hartmann, H. F. Morian, and R. Jedamzik, Proc. SPIE 4842, 56 (2003).

42. P. A. Baisden, L. J. Atherton, R. A. Hawley, T. A. Land, J. A. Menapace, P. E. Miller, M. J. Runkel, M. L. Spaeth, C. J. Stolz, T. I. Suratwala, P. J. Wegner, and L. L. Wong, Fusion Technol. 69, 295 (2017).

43. H. E. Hagy, Appl. Opt. 7, 833 (1968).

44. W. W. Jochs, H. J. Hoffmann, and N. M. Neuroth, J. NonCryst. Solids 102, 255 (1988).

45. G. Wang, Y. B. Liu, L. Z. Li, H. Zhang, L. Xie, F. M. Qiu, P. Ma, and D. Y. Yan, Proc. SPIE 10154, 1015410 (2016). 